\title{
Four-Wave-Mixing in Zirconia-Yttria-Aluminum Erbium Codoped Silica Fiber
}

H. Ahmad
harith@um.edu.my

M. C. Paul

\section{N. A. Awang}

\section{S. W. Harun}

M. Pal

\section{K. Thambiratnam}

Photonics Research Centre, Physics Department, University of Malaya, 50603 Kuala Lumpur, Malaysia Fiber Optics and Photonics Division, Central Glass \& Ceramic Research Institute-CSIR, Kolkata, India Faculty of Science, Technology and Human Development, Universiti Tun Hussein Onn Malaysia, 86400 Batu Pahat, Johor

Department of Electrical Engineering, Faculty of Engineering, University of Malaya, 50603 Kuala Lumpur Malaysia

Fiber Optics and Photonics Division, Central Glass \& Ceramic Research Institute-CSIR, Kolkata, India

The generation and characterization of the Four-Wave-Mixing (FWM) effect in an Erbium Doped Zirconia-Yttria-Alumino Silicate Fiber (EDZF) is described. The EZDF is fabricated from a conventional silica preform by Modified Chemical Vapour Deposition (MCVD) and also solution doping to add glass modifiers and nucleating agents, with the resulting preform annealed and drawn into a fiber strand with a $125 \pm 0.5 \mu \mathrm{m}$ diameter. A $4 \mathrm{~m}$ long EZDF, ZEr-B with a propagation loss of $0.68 \mathrm{~dB} / \mathrm{m}$ and an erbium concentration of 3000 ppm is used to investigate the FWM effect. The FWM power levels are measured to be approximately - $45 \mathrm{dBm}$ at a region of $1565 \mathrm{~nm}$ and show good agreement with the theoretical predicted values. A non-linear coefficient of $14 \mathrm{~W}^{-1} \mathrm{~km}^{-1}$ is also measured, along with chromatic and slope dispersion values of $28.45 \mathrm{ps} / \mathrm{nm} . \mathrm{km}$ and $3.63 \mathrm{ps} / \mathrm{nm}^{2} . \mathrm{km}$, which agree with the predicted values. The fabricated ZEr-B fibre has many potential applications utilizing the FWM effect, including the generation of multi-wavelength outputs.

[DOI: http://dx.doi.org/10.2971/jeos.2012.12011]

Keywords: Zirconia-Erbium doped fiber, non-linear optical phenomena, four-wave-mixing

\section{INTRODUCTION}

Fiber Optical Amplifiers (FOAs) are a key component in realizing the deployment of long range, high-speed and large capacity communication networks [1,2]. FOAs are able to effectively counter the attenuation and distortion of multiple signals travelling in optical transmission fibers at the same time [2] and have been widely used in Dense Wavelength Division Multiplexing (DWDM) and Optical Time Division Multiplexing (OTDM) systems. Furthermore, recent advances in technology have also opened up new possibilities for FOAs in a multitude of applications, including the generation of single and multi-wavelength outputs [3,4], wavelength conversion [5] and wide-band spectral sources [6].

The development of in-line optical amplification was necessitated by the need to overcome the switching and processing limitations of electronic regenerators which were the dominant means of amplification at the time [7, 8]. Initially, research efforts focused on methods such as Raman amplification [9, 10] Semiconductor Optical Amplifiers (SOAs) [11, 12] and Fiber Optic Parametrical Amplifiers (FOPAs) $[13,14]$ to amplify optical signals, but the cost and complexity of these methods made them commercially impractical. It was not until the early 1990s that a low-cost and commercially viable alternative was developed in the form of the Erbium Doped Fiber Amplifier (EDFA) [1]. EDFAs are capable of providing a wide amplification bandwidth and can be easily spliced to conventional silica fibers, making them the backbone of many optical networks worldwide.

Current research efforts have now focused towards the development of compact, high performance and low cost EDFAs. In this regard, new fibres such as thulium, phosphorus, tellurite, bismuth and photonic crystal fibres [15]-[20] have been explored to increase the erbium ion concentration in the fiber without detrimental effects such as concentration quenching [21] and cluster formation [22]. However, these new fibres are not without their drawbacks, for instance thulium and bismuth based fibers that cannot be spliced easily to conventional SMFs. In this regard, Zirconia has been seen as a highly promising candidate in the development of compact, high erbium concentration EDFAs. Zirconia or $\mathrm{ZrO}_{2}$ ions co-doped in silica fibers possess a high index of refraction that has been reported of around 1.45 over the visible and near infrared spectrum $[23,24]$. As such, $\mathrm{ZrO}_{2}$ ions tend to exhibit wide emission and absorption bandwidths, as predicted by the FuchtbauerLadenberg relationship [25, 26] and JuddOfelt theory [27, 28] 
and therefore can amplify more DWDM channels than lower index materials. Furthermore, zirconia has excellent mechanical strength and is chemical corrosion resistance as well as being non-hygroscopic, is easily spliced to SMFs and exhibits excellent transmission in the visible and near infrared; giving the zirconia doped EDFA practical applications in the real world. The fabrication and characterization of an Erbium Doped Zirconia-Yttria-Alumino Silicate Fiber (EDZF) is the focus of the first part of this work.

Additionally, zirconia co-doped fibers have also been shown to exhibit significant non-linear characteristics. These nonlinear characteristics, which are not seen in conventional Single-Mode Fibres (SMFs) or EDFAs, [1] have tremendous potential for the development of various new applications such as multi-wavelength outputs and also wavelength conversion. Of particular interest is the Four-Wave Mixing (FWM) effect. In the absence of significant photo-absorption effects, FWM is a type of optical Kerr effect, and occurs when light at two or more different wavelengths is launched into a fiber [1]. The FWM effect is observed when signals at different wavelengths are launched into a fiber, and the interaction of these two signals gives rise to a new signal (known as an idler), the wavelength of which does not coincide with any of the others $[29,30]$. The FWM effect has tremendous potential for the development of new fiber based wavelength sources, and is the focus of the later part of this work.

\section{ZIRCONIA YTTRIA-ALUMINO SILICATE GLASS FABRICATION}

The EDZF is fabricated in three stages. In the first stage, a conventional silica preform is fabricated using the Modified Chemical Vapour Deposition (MCVD) technique, whereby $\mathrm{SiCl}_{4}$ and $\mathrm{P}_{2} \mathrm{O}_{5}$ vapors are passed through a slowly rotating silica tube that is heated by an external burner. The burner heats the length of the tube as it rotates and, due to the high temperature generated, the chloride in the $\mathrm{SiCl}_{4}$ and $\mathrm{P}_{2} \mathrm{O}_{5}$ vapors oxidizes, depositing a porous phospho-silica layer along the inner wall of the silica tube. The optimum deposition temperature range for the MCVD process is $1350-1400{ }^{\circ} \mathrm{C}$, with a variation of the pre-sintering temperature from 1300 to $1450{ }^{\circ} \mathrm{C}$. The fabricated silica tube, with its deposited porous phospho-silica layer, then undergoes a solution doping process using dopant precursors of suitable strength to obtain the optimized process parameters for making a fiber with a Numerical Aperture (NA) of approximately $0.17-0.20$. The glass modifiers, $\mathrm{ZrO}_{2}, \mathrm{Y}_{2} \mathrm{O}_{3}, \mathrm{Al}_{2} \mathrm{O}_{3}$ and $\mathrm{Er}_{2} \mathrm{O}_{3}$ are individually mixed with alcohol and water at a ratio of 1:5 to form the complex ions $\mathrm{ZrOCl}_{2} \cdot 8 \mathrm{H}_{2} \mathrm{O}, \mathrm{YCl}_{3} \cdot 6 \mathrm{H}_{2} \mathrm{O} \mathrm{AlCl}_{3} \cdot 6 \mathrm{H}_{2} \mathrm{O}$ and $\mathrm{ErCl}_{3} \cdot 6 \mathrm{H}_{2} \mathrm{O}$ respectively and are then incorporated into the host matrix using the solution doping technique. Small quantities of $\mathrm{Y}_{2} \mathrm{O}_{3}$ and $\mathrm{P}_{2} \mathrm{O}_{5}$ are also added to the glass matrix to act as nucleating agents, functioning to increase the phase separation of the $\mathrm{Er}_{2} \mathrm{O}_{3}$ doped micro-crystallites that will form in the core matrix of the optical fiber preform.

During the fabrication process, it is crucial to note that, in a bulk glass matrix, pure zirconia exists in three distinct crystalline phases over different temperature ranges. At very high temperatures, above $2350{ }^{\circ} \mathrm{C}, \mathrm{ZrO}_{2}$ has a cubic structure whereas, at intermediate temperatures between 1170 and $2350{ }^{\circ} \mathrm{C}$, a tetragonal structure is observed. At low temperatures, below approximately $1170{ }^{\circ} \mathrm{C}, \mathrm{ZrO}_{2}$ takes on a monoclinic structure. The transformation of the crystalline structure from tetragonal to monoclinic is very rapid and is accompanied by a 3 to 5 percent volume increase. This rapid increase can result in extensive cracking in the material - as was observed in the doped core region of the preform after the fabrication - and is highly detrimental, as it destroys the mechanical properties of fabricated components during cooling. In order to overcome this problem, several oxides, such as $\mathrm{MgO}$, $\mathrm{CaO}$, and $\mathrm{Y}_{2} \mathrm{O}_{3}$ that dissolve in the zirconia crystal structure can be used to slow down or eliminate these crystal structure changes; in this work a minor quantity of $\mathrm{Y}_{2} \mathrm{O}_{3}$ is used.

In the final stage of the fiber fabrication process, the fabricated preform that has undergone the solution doping process is annealed at $1100{ }^{\circ} \mathrm{C}$ for 3 hours in a closed furnace, under heating and cooling rates of $20^{\circ} \mathrm{C} / \mathrm{min}$, to generate $\mathrm{ErO}_{2}$ doped $\mathrm{ZrO}_{2}$ rich micro-crystalline particles. The resulting annealed preform is collapsed into a solid rod at a temperature higher than $2000{ }^{\circ} \mathrm{C}$ and is drawn into a fiber strand with a diameter $125 \pm 0.5 \mu \mathrm{m}$, using a conventional fiber drawing tower. During the drawing process, the preform (and the fiber obtained) is exposed to a temperature of around $2000{ }^{\circ} \mathrm{C}$ for only a few minutes. Due to the high cooling rate of the material and the melting temperature of the $\mathrm{ZrO}_{2}$ crystals being above $2200{ }^{\circ} \mathrm{C}$, the $\mathrm{ZrO}_{2}$ nano-crystalline host is retained within the silica glass matrix. Both the primary \& secondary coatings were applied on-line to increase the tensile strength, as well as to reduce the moisture ingress from external sources. During the fiber drawing procedure, proper control of the fiber diameter, coating thickness and coating concentricity along the whole length of the fabricated fiber gives the optimization required for the production of a high quality optical fiber. The thickness of the primary coating (Desolite DP-1004), as well as that of the secondary coating (Desolite DS-2015), and the coating uniformity were ensured by adjusting the flow pressure of the inlet gases into the primary and secondary coating resin vessels during the drawing of the fiber, as well as by properly aligning the position of primary and secondary coating cup units.

\section{EZDF CHARACTERISATION}

In bulk zirconia-silicate glass, phase-separation has been observed at temperatures below the onset of crystallization which also results in structural inhomogeneity [31, 32]. Phase separation, or immiscibility, is a phenomenon that is known to exist in amorphous binary systems [33]; however in some $\mathrm{ZrO}_{2}-\mathrm{SiO}_{2}$ systems immiscibility exists even in the stable liquid phase above the melting point. The phase diagram of $\mathrm{ZrO}_{2}-\mathrm{SiO}_{2}$ systems was evaluated using Fact-Sage software, and it was determined that a stable immiscibility zone exists in the range between 60 and 80 mole $\% \mathrm{SiO}_{2}$. This stable immiscibility zone extends to temperatures lower than the glass melting point - and gives a metastable immiscibility zone in a wide composition range where phase separation occurs normally in an amorphous state. In the EZDF, it may be expected 


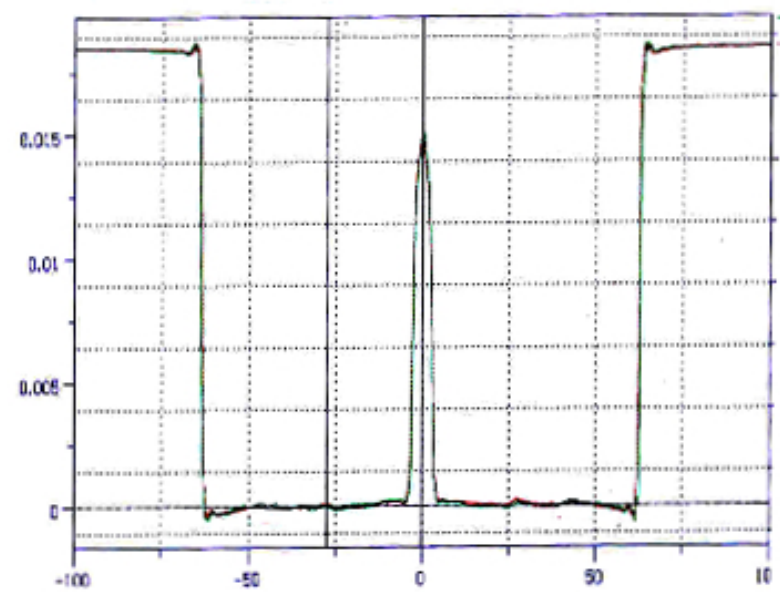

FIC. 1 Refractive index profile of fiber (ZEr-B).

\begin{tabular}{llll}
\hline Perform No & $\begin{array}{l}\mathrm{Al}_{2} \mathrm{O}_{3} \\
(\text { mole \%) }\end{array}$ & $\begin{array}{l}\mathrm{ZrO}_{2} \\
(\text { mole \%) }\end{array}$ & $\begin{array}{l}\mathrm{Er}_{2} \mathrm{O}_{3} \\
(\text { mole \%) }\end{array}$ \\
\hline ZEr-A & 0.25 & 0.65 & 0.155 \\
ZER-B & 0.24 & 2.10 & 0.225 \\
\hline
\end{tabular}

TABLE 1 Doping levels within core region of the preforms

that the separated $\mathrm{ZrO}_{2}$ and $\mathrm{Al}_{2} \mathrm{O}_{3}$ phases would mix together into a homogeneous mixture before crystallization could occur during heating at high temperature, since the homogeneous amorphous mixture of compositions, $\mathrm{ZrAl}_{x} \mathrm{O}_{y}$, is generally thermodynamically more stable than the two separate phases. In this work two $\mathrm{Er}_{2} \mathrm{O}_{3}$ doped fibers, designated ZEr$\mathrm{A}$ and $\mathrm{ZEr}-\mathrm{B}$, were fabricated. Both fibers contain 0.24-0.25 mole \% of $\mathrm{Al}_{2} \mathrm{O}_{3}$, with the $\mathrm{ZrO}_{2}$ and $\mathrm{Er}_{2} \mathrm{O}_{3}$ dopant concentration increased from 0.65 to 2.21 mole \% and from 0.155 to 0.225 mole \% for ZEr-A and ZEr-B respectively. The doping levels of the two fibers are obtained through an Electron Probe Micro-Analysis (EPMA) for both the fabricated fiber samples and is given in Table 1, whilst the physical parameters of the fibers are given in Table 2.

The measured refractive index profile of fiber ZEr-B is shown in Figure 1. The spectroscopic properties such as absorption coefficient, fluorescence and fluorescence decay curves of the fabricated fibers are measured, and it can be observed that the peak absorption of the two types of fiber at $978 \mathrm{~nm}$ are found to be 15.0 and $22.0 \mathrm{~dB} / \mathrm{m}$ respectively. The spectral attenuation curve of fiber ZEr-B is shown in Figure 2, as the non-linear properties of this fiber will be analysed in the following section.

The fluorescence spectra of the fiber samples were measured with lateral pumping, for a pump power level of $100 \mathrm{~mW}$ at $980 \mathrm{~nm}$. The fluorescence curves for both fibers are shown in Figure 3 and the fluorescence decay curves of both fibers are shown in Figure 4.

The two fibers (ZEr-A and ZEr-B) show almost the same fluorescence live-times of 10.93 and $10.86 \mathrm{~ms}$ respectively. Fiber ZEr-B, which has higher doping levels of $\mathrm{Er}_{2} \mathrm{O}_{3}$ and $\mathrm{ZrO}_{2}$ shows slight shorter fluorescence life-time. These results indicate that the concentration-quenching phenomenon that is

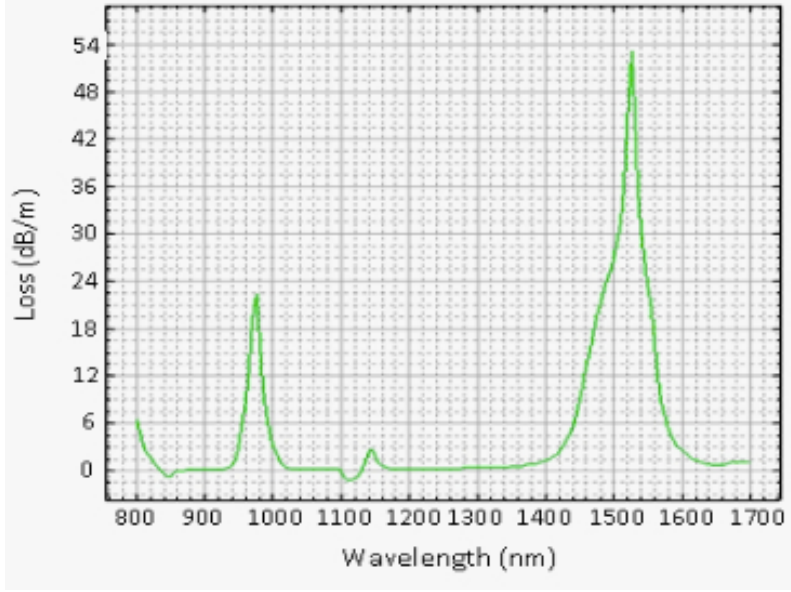

FIG. 2 Spectral attenuation curve of fiber (ZEr-B).

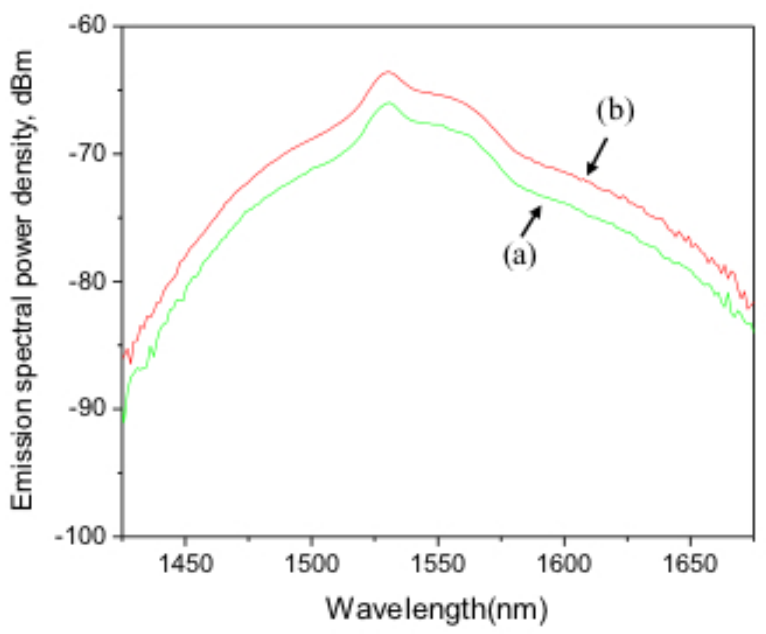

FIG. 3 Fluorescence curves of (a) fiber ZEr-A and (b) fiber ZEr-B at a pump power level of $100 \mathrm{~mW}$.

typical of $\mathrm{Er}^{3+}$ ions is strongly reduced through an increase in the doping levels of $\mathrm{ZrO}_{2}$. In the generation of the FWM effect in the zirconia-erbium doped silica fiber, the ZEr-B is used instead of the $\mathrm{ZEr}-\mathrm{A}$ due to the higher $\mathrm{ZrO}_{2}$ concentration, which will provide a better non-linear interaction.

\section{GENERATION OF THE FWM EFFECT IN THE EZDF}

The generation of the FWM effect in nonlinear fibers can be explained by using the coupled differential equations for the propagating amplitudes, including the contributions to phase mismatch due to XPM and SPM [34]. A well-known formula used for FWM estimation was originally derived by Hill et. al. [35] and reformulated later to include the phase-mismatch dependent efficiency by Shibata et. al. [36]. In the FWM process in glass, two chosen wavelengths ( $\lambda_{\text {pump }}$ and $\left.\lambda_{\text {signal }}\right)$ will generate a converted wavelength $\lambda_{\text {converted_signal }}=2 \lambda_{\text {pump }}-\lambda_{\text {signal }}$. To analyze the nonlinearity in the EZDF, the nonlinear coefficient, $\gamma$, is estimated by using;

$$
\gamma=\sqrt{P_{\text {textFMW }}} \eta P_{S} P_{P}^{2} e^{-\alpha L} L_{\text {textef }} f^{2}
$$




\begin{tabular}{|c|c|c|c|c|c|c|}
\hline Fiber Number & Core Composition & Core Diameter & Fiber Type & NA & A-eff & RI of core \\
\hline ZEr-A & $\begin{array}{l}\mathrm{SiO}+\mathrm{Al}_{2} \mathrm{O}_{3}+\mathrm{P}_{2} \mathrm{O}_{5}-\mathrm{ZrO}_{2^{-}} \\
\mathrm{Y}_{2} \mathrm{O}_{3}+\mathrm{Er}_{2} \mathrm{O}_{3}\end{array}$ & 10.5 & Circular core with normal resin & 0.17 & $87 \mu^{2}$ & 1.46625 \\
\hline ZEr-B & $\begin{array}{l}\mathrm{SiO}+\mathrm{Al}_{2} \mathrm{O}_{3}+\mathrm{P}_{2} \mathrm{O}_{5}-\mathrm{ZrO}_{2-} \\
\mathrm{Y}_{2} \mathrm{O}_{3}+\mathrm{Er}_{2} \mathrm{O}_{3}\end{array}$ & 10.0 & Circular core with normal resin & 0.20 & $75 \mu^{2}$ & 1.47025 \\
\hline
\end{tabular}

TABLE 2 Fiber parameters

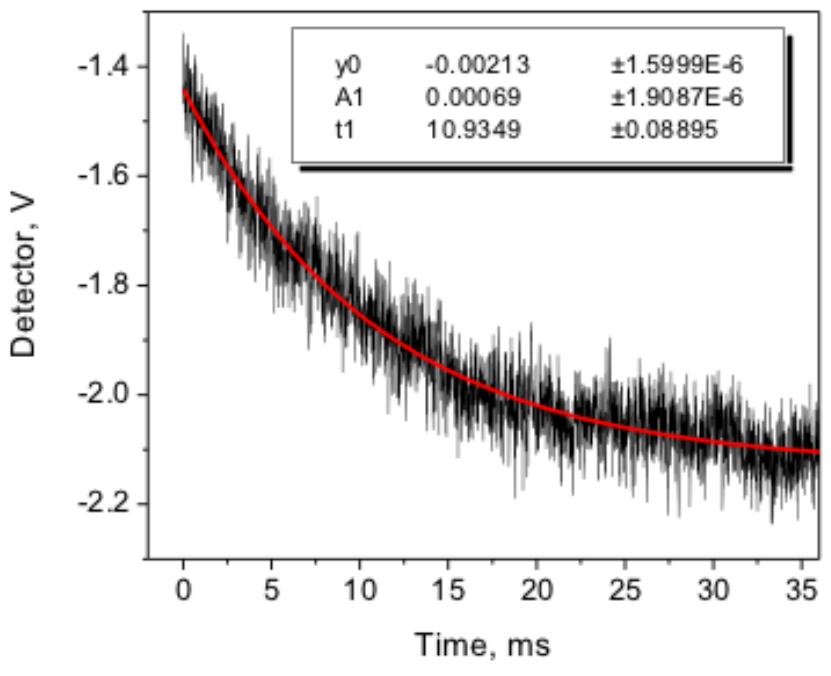

(a)

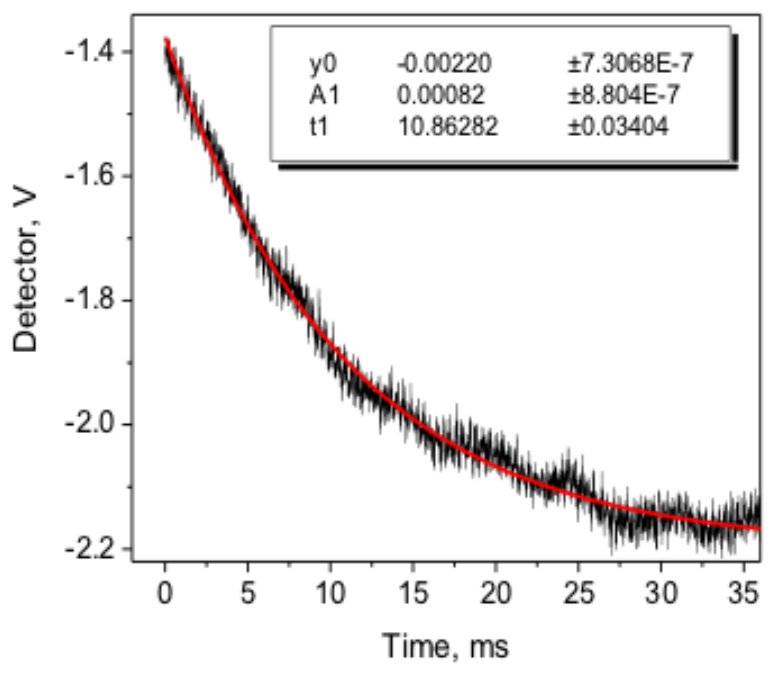

(b)

FIG. 4 The fluorescence decay curve of two EDFs (a) ZEr-A and (b) ZEr-B at a pump power level of $100 \mathrm{~mW}$.

where $P_{\mathrm{FWM}} \mid$ is the FWM power, $P_{P}$ is the input pump power, $P_{S}$ is the input signal power, $L$ is the fiber length and $\alpha$ is the fiber attenuation coefficient. The effective length of the fiber $L_{\text {eff }}$ takes into account the decrease in power due to attenuation - and is defined as;

$$
L_{e f f}=\frac{1-e^{-\alpha L}}{\alpha}
$$

The normalized FWM efficiency, $\eta$, is written as;

$$
\eta=\frac{\alpha^{2}}{\alpha^{2}+\Delta \beta^{2}}\left[1+\frac{2 e^{-\alpha L}(1-\cos (\Delta \beta L))}{\left(1-e^{\alpha L}\right)^{2}}\right]
$$

where is the phase $\Delta \beta$ mismatch that is given by;

$$
\Delta \beta=\frac{2 \pi \lambda^{2}}{c} D \Delta f^{2}
$$

with the dispersion parameter, $D=\frac{-2 \pi c}{\lambda^{2}} \beta^{2}$, where $\beta^{2}$ is the group velocity dispersion parameter. From equation (4), it can be seen that $P_{\text {FMW }}$ is at its minima when $\Delta \beta \frac{L}{2}=k \pi$, where $k$ is an integer. This occurs due to the phase mismatch between the signals propagating inside the fiber and occurs at every $\frac{2 \pi}{\beta}$ meters. The $P_{\text {FMW }}$ minima can also be determined as a product of the channel spacing, such that:

$$
\Delta f_{k}=\sqrt{\frac{k c}{\lambda^{2} D L}}
$$

As the magnitude of the nonlinearity in the fiber only shifts the $P_{\text {FMW }}$ minima, therefore an analysis of the FWM signal power minima can be used to determine the dispersion of the optical fiber, whilst the nonlinearity can be estimated from the total fiber attenuation. The physical setup for measuring the
$P_{\text {FMW }}$ minima is simple and only requires two laser diodes with a tuning range of less than $1 \mathrm{~nm}$ each and a EZDF of the proper length. The channel spacing at which $P_{\text {FMW }}$ reaches its first minima is a necessary measurement in calculating the dispersion of the fiber and is given as:

$$
D=\frac{c}{\lambda^{2} \Delta f^{2} L}
$$

From equations (1) to (6), the theoretical FWM power can now be calculated as

$$
P_{\mathrm{FMW}}=\eta \gamma^{2} P_{p}^{2} P_{s} e^{-\alpha L} L_{e f f}^{2}
$$

$\gamma$ is determined by bi-directional measurements of the FWM power, while the chromatic dispersion is determined from the wavelength detuning of the FWM Power Conversion Efficiency (PCE). Both measurements use the same experimental setup as given by the schematic in Figure 5 .

In the setup, two Yokogawa (AQ2200) Tunable Laser Sources (designated TLS1 and TLS2), with tuning ranges from $1460 \mathrm{~nm}$ to $1640 \mathrm{~nm}$ and linewidths of $0.015 \mathrm{~nm}$ are used as signal sources. The pump signal $\mathrm{P}_{1}\left(\right.$ or $\mathrm{P}_{P}$ ), is generated by TLS 1 at a fixed wavelength of $1560 \mathrm{~nm}$ and an average output power of $12.8 \mathrm{dBm}$. A second signal, $\mathrm{P}_{S}$ is generated from TLS2 with a wavelength varying from $1561 \mathrm{~nm}$ to $1565 \mathrm{~nm}$ at an average power level of $10.8 \mathrm{dBm}$. Both $\mathrm{P}_{1}$ and $\mathrm{P}_{\mathcal{S}}$ are combined using a $3 \mathrm{~dB}$ coupler and a Polarization Controller (PC) to adjust the polarization of the input signals in order to obtain the maximum FWM efficiency. Additionally, two Laser Diode (LD) pumps at wavelengths of $1460 \mathrm{~nm}$ and $1490 \mathrm{~nm}$ are also launched into the EZDF using a WDM to excite the $\mathrm{Er}^{3+}$ ions just enough so that they are transparent to the 


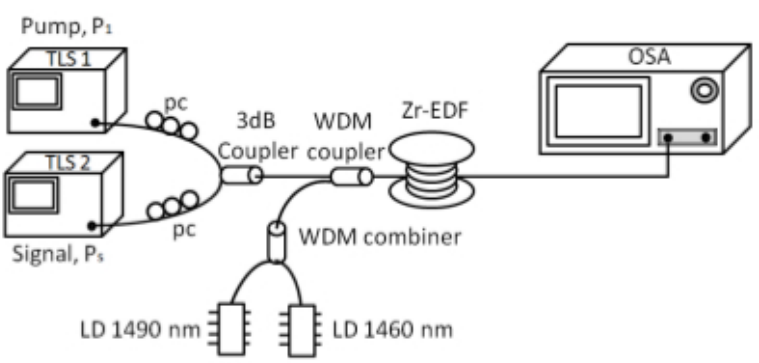

FIG. 5 Schematic diagram for generating FWM effects in the EZDF

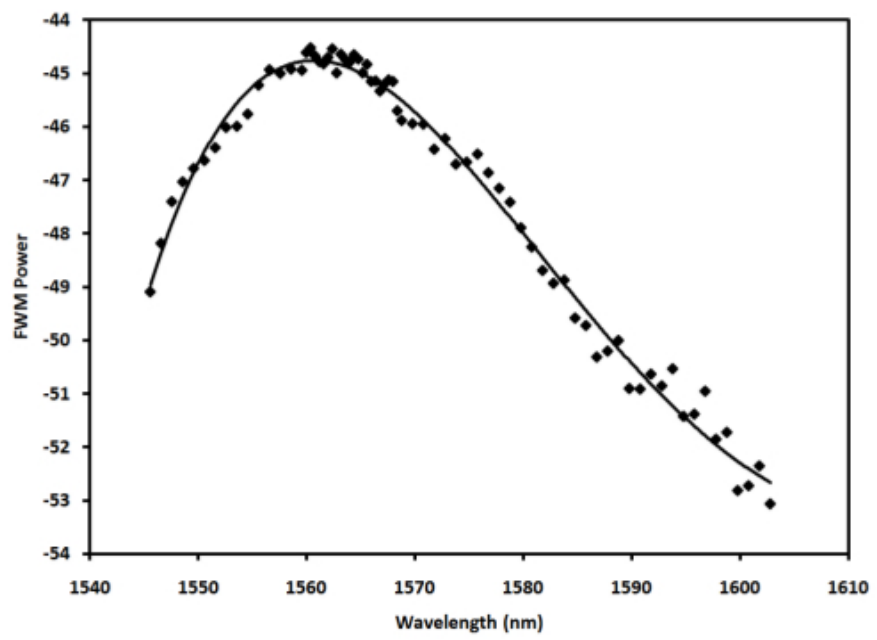

FIC. 6 The spectrum of the converted signal (FWM power) against the wavelength of the pump against converted wavelength for the ZEr-B optical fiber sample.

signals used for the generation of the FWM (the suppression of the $\mathrm{Er}^{3+}$ ions is necessary as the EZDF sample incorporates both $\mathrm{ZrO}_{2}$ and $\mathrm{Er}_{2} \mathrm{O}_{3}$, however this work is only interested in the non-linear effects generated by the $\mathrm{ZrO}_{2}$ in the fibre). A $4 \mathrm{~m}$ long ZEr-B fiber with an Erbium concentration of $3000 \mathrm{ppm}$ is used. The ZEr-B fiber has a core refractive index value of 1.466 and an effective area of $87 \mu \mathrm{m}^{2}$ along with a propagation loss, $\alpha$ of $0.68 \mathrm{~dB} / \mathrm{m}$, which is obtained using the cut-back method. The refractive index and glass core size of the ZEr-B fiber used are important parameters that will be used to determine the nonlinearity of the fiber. Finally, a Yokogawa Optical Spectrum Analyzer (OSA) with $0.02 \mathrm{~nm}$ resolution bandwidth is used to measure the generated FWM spectrum.

\section{RESULTS AND DISCUSSION}

The power of signals generated by the FWM process is dependent the wavelength of the pump and input signal. In this work, the pump and signal wavelengths are detuned by $0.4 \mathrm{~nm}$. The pump and signal powers are set at $+15 \mathrm{dBm}$ and $+13 \mathrm{dBm}$ respectively and are optimized for the maximum possible power using a PC. Figure 6 shows the power of the signal obtained from the FWM process against the pump wavelength.

It can be seen that the power of the converted signal begins to increase from a low value of $-48 \mathrm{dBm}$ at a pump wavelength of $1545 \mathrm{~nm}$ to a peak power of $-45 \mathrm{dBm}$ at $1565 \mathrm{~nm}$. The power of the converted signal does not change signifcantly between $1558 \mathrm{~nm}$ to $1565 \mathrm{~nm}$, with only minor fluctuations of approximately $0.5 \mathrm{~dB}$ being observed. After this region however, the power decreases rapidly as the pump power continues to increase towards the L-band region. The reason for this is that the gain spectrum of ZEr-B provides the highest gains at a wavelength around $1560 \mathrm{~nm}$. As such, the pump signal is set at a wavelength of $1560 \mathrm{~nm}$, as this will ensure the generation of the FWM output will fall within the flat region. The wavelength value of $1560 \mathrm{~nm}$ is also used in the measurement of the nonlinearity coefficient of ZEr-B.

Figure 7 shows the overlay spectrum of the converted signals along with the pump and signal wavelengths. The spectrum shown is as obtained from the OSA with a $+25 \mathrm{~dB}$ fixed attenuator, the attenuator serving to protect the OSA from spikes in the signal which could potentially damage it. The pump wavelength is left constant at $1560 \mathrm{~nm}$ and $-9.9 \mathrm{dBm}$ power while the signal wavelengths are varied from $1561 \mathrm{~nm}$ to $1565 \mathrm{~nm}$ in steps of $1 \mathrm{~nm}$. The power of the signal wavelength is maintained at $-10.5 \mathrm{dBm}$. From Figure 7, it can be seen that two sidebands $C_{1}$ and $S_{2}$ are generated by the pump and signal wavelengths. At a signal wavelength of $1561 \mathrm{~nm}$, two converted wavelengths are observed at $1559 \mathrm{~nm}\left(C_{1}\right)$ and $1562 \mathrm{~nm}\left(\mathrm{~S}_{2}\right)$, a shift of 2 and $1 \mathrm{~nm}$ respectively on either side of the signal. As the signal wavelength increases to $1562 \mathrm{~nm}$, the converted wavelengths also shift accordingly to $1558 \mathrm{~nm}$ $\left(\mathrm{C}_{1}\right)$ and $1564 \mathrm{~nm}\left(\mathrm{~S}_{2}\right)$, giving a shift of 4 and $2 \mathrm{~nm}$ respectively. This trend is seen to continue as the signal wavelength continues to be varied until $1565 \mathrm{~nm}$, which sees the $C_{1}$ move towards a wavelength of $1555 \mathrm{~nm}$ in steps of $1 \mathrm{~nm}$, and $S_{2}$ increasing in steps of $2 \mathrm{~nm}$ to a wavelength of $1570 \mathrm{~nm}$. It is also observed that when the signal wavelength increases at a fixed pump wavelength, the power of the generated sidebands drops. This can be attributed to the gain spectrum of the ZEr-B fiber such that the longer signal wavelengths move away from the optimum gain region of the fiber. The channel spacings obtained in Figure 8 are essential in determining the fiber non-linear coefficient, dispersion and slope dispersion of the ZEr-B fiber, which is seen in the following results.

Figure 8 shows the power of the converted signal, $C_{1}$ against the wavelength of the input signal. The pump is left constant at a wavelength of $1560 \mathrm{~nm}$ and the signal wavelength is varied from $1550 \mathrm{~nm}$ to $1559 \mathrm{~nm}$ with a frequency spacing $0.2 \mathrm{~nm}$. To ensure the maximum power is obtained for the converted signal, the two PCs as shown in Figure 6 are adjusted to provide the optimum output power. As can be seen from the figure, the power of the converted signal is initially low at about $-58 \mathrm{dBm}$. However, as the signal wavelength increases, so does the power of the converted signal, reaching a power of approximately $-45 \mathrm{dBm}$ at a wavelength of $1559 \mathrm{~nm}$. Further increases in the input signal wavelength do not result in any change to the converted signal power. It can be seen that the experimental results agree well with the theoretical predictions for ZEr-B. It is observed that the difference in the power of the converted signal in Figure 9 and that of Figure 8 is attributed to the use of the $+25 \mathrm{~dB}$ attenuator.

The analysis of FWM power in a function of channel spacing can be used to estimate the fiber chromatic dispersion 


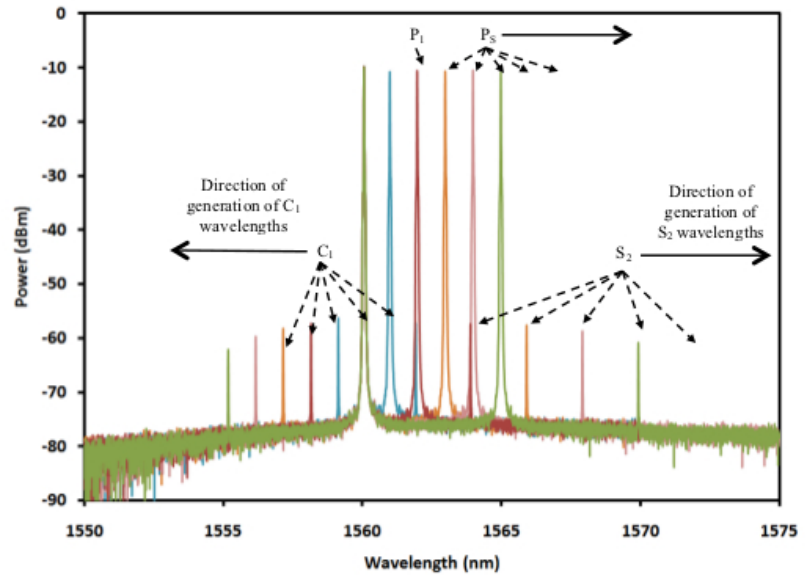

FIC. 7 The typical output spectra at $P_{1}$ and $P_{s}$, as well as their converted signals (sideband fields) $C_{1}$ and $S_{2}$ when wavelength of $P_{1}$ is fixed at $1560 \mathrm{~nm}$ and the wavelength of $P_{S}$ is varied from $1561 \mathrm{~nm}$ to $1565 \mathrm{~nm}$ for the ZEr-B optical fiber sample.

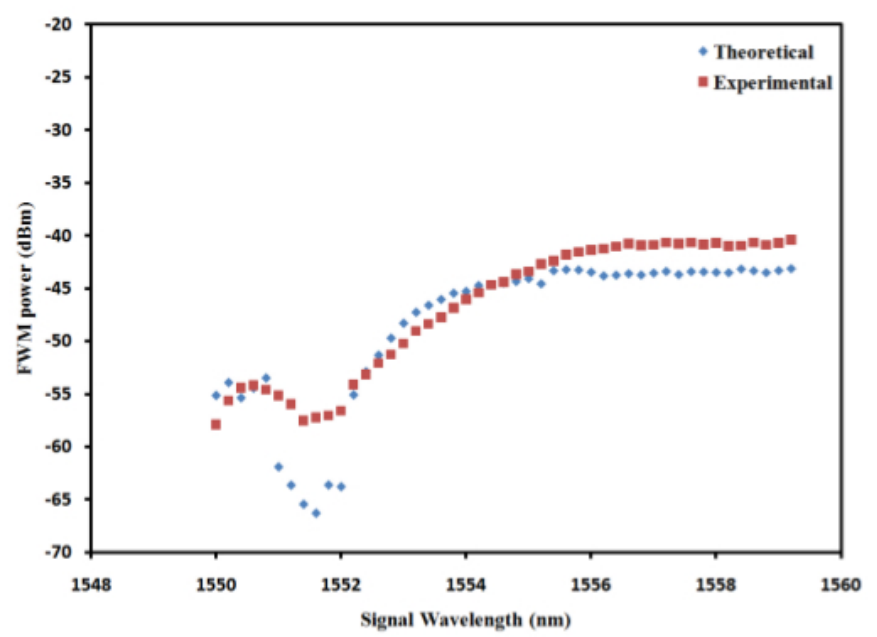

FIC. 8 FWM conversion efficiency versus wavelength detuning for the ZEr-B optical fiber sample.

and dispersion slope. Figure 9 shows the normalized FWM efficiency against the input signal frequency. It can be seen that as the channel spacing (frequency) is increased from $30 \mathrm{GHz}$ to $400 \mathrm{GHz}$, the FWM efficiency remains relatively the same, with fluctuations of about 0.5 a.u. However, above $400 \mathrm{GHz}$, the FWM efficiency begins to drop, reaching almost 0 at $1000 \mathrm{GHz}$. These measurements are in agreement with the theoretical predictions for the ZEr-B fiber. From equation (6) and the Figure 9, a chromatic dispersion and slope dispersion value of $28.45 \mathrm{ps} / \mathrm{nm} . \mathrm{km}$ and $3.63 \mathrm{ps} / \mathrm{nm}^{2} . \mathrm{km}$ respectively is obtained for ZEr-B.

Using the signal power, pump power, converted power and the normalized FWM efficiency, the nonlinear coefficient for $\mathrm{Zr}$-EDF is estimated using equation (1). In this equation, the FWM efficiency is important in getting the value of nonlinear coefficient where it used equation (3) for found the value. Therefore, a nonlinear coefficient value of $14 \mathrm{~W}^{-1} \mathrm{~km}^{-1}$ is obtained for the ZEr-B. Figure 10 shows the variation of the nonlinear coefficient against the channel spacing.

From Figure 10, it can be seen that the non-linear coefficient

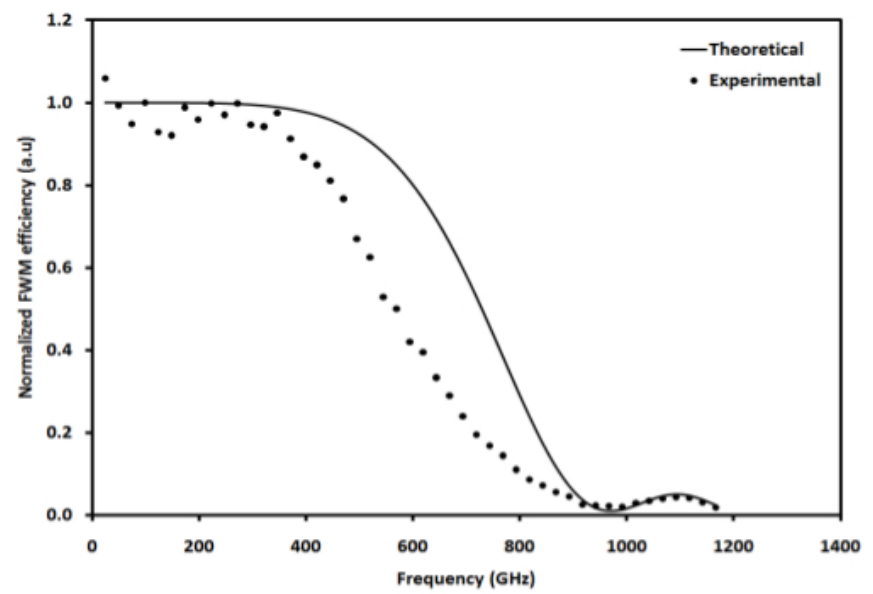

FIG. 9 Normalized FWM efficiency against the input signal frequency for the ZEr-B optical fiber sample.

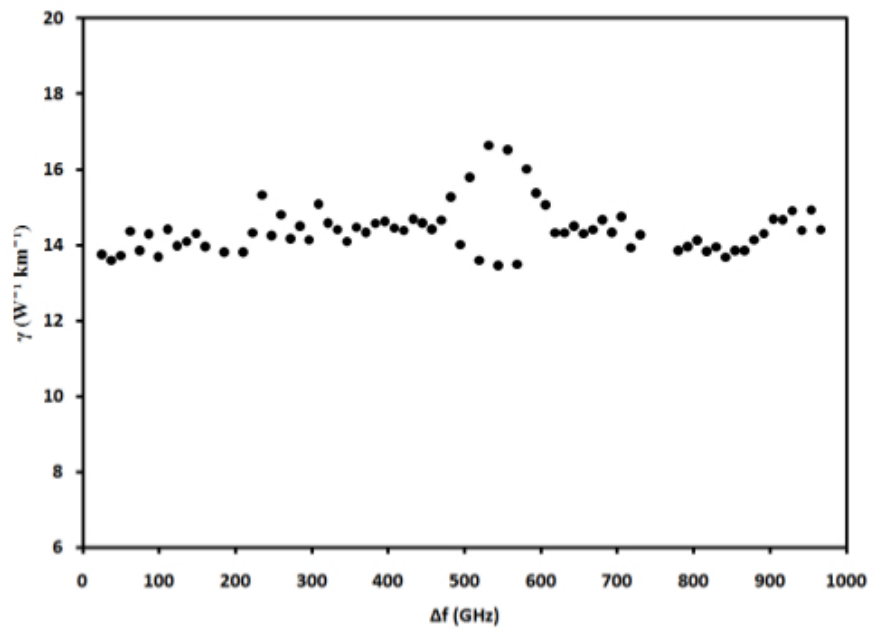

FIG. 10 Nonlinear coefficients with varying the frequency spacing as obtained using the ZEr-B optical fiber sample.

remains the same for almost all channel spacing values, with the largest variation being approximately $2 \mathrm{dBm}$ between the region of 500 to $600 \mathrm{GHz}$. This gives the ZEr-B fiber a high potential as a medium for a variety of applications such as wavelength conversion and wavelength generation.

\section{CONCLUSIONS}

The fabrication of an EDZF is described in the work, followed by an analysis of its application as a non-linear medium for the generation of the FWM effect. The fabrication of the EZDF follows the conventional approach with the creation of a standard silica preform using the MCVD technique. Glass modifiers and nucleating agents are then added to the silica preform using the solution doping technique and the resulting preform is annealed and drawn into a fiber strand with a diameter $125 \pm 0.5 \mu \mathrm{m}$. In this work, two EZDF samples are fabricated and designated as ZEr-A and ZEr-B, with $\mathrm{ZrO}_{2}$ and $\mathrm{Er}_{2} \mathrm{O}_{3}$ dopant concentrations of 0.65 to 2.21 mole \% and 0.155 to 0.225 mole \% respectively and numerical apertures of between 0.17 to 0.20 as well as peak absorptions of 15.0 
and $22.0 \mathrm{~dB} / \mathrm{m}$ respectively at $978 \mathrm{~nm}$. In investigation FWM effect, a $4 \mathrm{~m}$ long portion of ZEr-B with a propagation loss of $0.68 \mathrm{~dB} / \mathrm{m}$ and an erbium concentration of $3000 \mathrm{ppm}$ is used. FWM power levels of approximately $-45 \mathrm{dBm}$ at around $1565 \mathrm{~nm}$ are obtained and agree well with the theoretical predicted values. The ZEr-B fiber also shows a non-linear coefficient of $14 \mathrm{~W}^{-1} \mathrm{~km}^{-1}$ along with chromatic and dispersion slopes of $28.45 \mathrm{ps} / \mathrm{nm} . \mathrm{km}$ and $3.63 \mathrm{ps} / \mathrm{nm}^{2} . \mathrm{km}$ that are well in accordance to the theoretical values.

\section{References}

[1] G. E. Keiser, "A Review of WDM Technology and Applications," Opt. Fiber Technol. 5, 3-39 (1999).

[2] M. Wasfi, “Optical Fiber Amplifiers - Review," Int. J. Comm. Netw. Infor. Sec. 1, 42-47 (2009).

[3] H. Ahmad, M. Z. Zulkifli, A. A. Latif, K. Thambiratnam, and S. W. Harun, "17-channels $S$ band multiwavelength Brillouin/Erbium Fiber Laser Co-Pump with Raman source," Laser Phys. 19, 2188-2193 (2009).

[4] D. Richardson, J. Nilsson, and W. Clarkson, "High Power Fiber Lasers: Current Status and Future Perspectives [Invited]," J. Opt. Soc. Am. B 27, 63-92 (2010).

[5] K. Inoue, and H. Toba, "Wavelength Conversion Experiment using Fiber Four-Wave Mixing," IEEE Photonic. Tech. L. 4, 69-72 (1992).

[6] E. Yahel, and A. Hardy, "Amplified Spontaneous Emission in High-Power, $\mathrm{Er}^{3+} . \mathrm{Yb}^{3+}$ Codoped Fiber Amplifiers for WavelengthDivision-Multiplexing Applications," J. Opt. Soc. Am. B 20, 1198-1203 (2003).

[7] D. Cotter, and A. D. Ellis, "Asynchronous Digital Optical Regeneration and Networks," J. Lightwave Technol. 16, 2068-2080 (1998).

[8] S. Abbott, "Review of 20 Years of Undersea Optical Fiber Transmission System Development and Deployment since TAT-8," in Proceedings to Optical Communication, 2008. ECOC 2008. 34th European Conference on, 1-4 (ECOC, Brussel, 2008).

[9] K. Rottwitt, and J. H. Povlsen, "Analysing the Fundamental Properties of Raman Amplifiers in Optical Fibers," J. Lightwave Technol. 23, 3597-3613 (2005).

[10] J. H. Lee, Y. M. Chang, Y. G. Han, H. Chung, S. H. Kim, and S. B. Lee, "A Detailed Experimental Study on Single Pump Raman/EDFA Hybrid Amplifiers: Static, Dynamic, and System Performance Comparison," J. Lightwave Technol. 23, 3848 (2005).

[11] P. Doussiere, A. Jourdan, G. Soulage, P. Garabedian, C. Graver, T. Fillion, E. Derouin, and D. Leclerc, "Clamped Gain Travelling Wave Semiconductor Optical Amplifier for Wavelength Division Multiplexing Applications," in Proceedings to Semiconductor Laser Conference, 1994., 14th IEEE International, 185-186 (IEEE, Maui, 1994).

[12] K. Morito, "Output-Level Control of Semiconductor Optical Amplifier by External Light Injection," J. Lightwave Technol. 23, 4332-4341 (2005).

[13] T. Torounidis, P. A. Andrekson, and B.-E. Olsson, "Fiber-optical parametric amplifier with 70-dB gain," IEEE Photonic. Tech. L. 18, 1194-1196 (2006).

[14] J. M. Chavez Boggio, P. Dainese, F. Karlsson, and H. L. Fragnito, "Broad-Band 88\% Efficient Two-Pump Fiber Optical Parametric Amplifier," IEEE Photonic. Tech. L. 15, 1528-1530 (2003).

[15] Y. Ohishi, A. Mori, M. Yamada, H. Ono, Y. Nishida, and K. Oikawa, "Gain Characteristics of Tellurite-Based Erbium-Doped Fiber Am- plifiers for 1.5- $\mu \mathrm{m}$ Broadband Amplification," Opt. Lett. 23, 274 (1998).

[16] S. Jiang, B.-C. Hwang, T. Luo, K. Seneschal, F. Smektala, S. Honkanen, J. Lucas, and N. Peyghambarian, "Net Gain of $15.5 \mathrm{~dB}$ from a $5.1 \mathrm{~cm}$-Long $\mathrm{Er}^{3+}$ Doped Phosphate Class Fiber," in Proceedings to Optical Fiber Communications, PD5-1 (IEEE, Baltimore, 2000).

[17] A. Cucinotta, F. Poli, and S. Selleri, "Design of Erbium-Doped Triangular Photonic-Crystal-Fiber-Based Amplifiers," IEEE Photonic. Tech. L. 16, 2027 (2004).

[18] S. Aozasa, H. Masuda, and M. Shimizu, "S-band Thulium-Doped Fiber Amplifier Employing High Thulium Concentration Doping Technique," J. Lightwave Technol. 24, 3842-3848 (2006).

[19] S. W. Harun, N. Tamchek, S. Shahi, and H. Ahmad, "L-band Amplification and Multi-Wavelength Lasing with Bismuth-Based Erbium Doped Fiber," Prog. Electromagn. Res. 6, 1-12, (2009).

[20] S. D. Emami, P. Hajireza, F. Abd-Rahman, H. A. Abdul-Rashid, H. Ahmad, and S. W. Harun, "Wide-Band Hybrid Amplifier Operating in S-Band Region," Prog. Electromagn. Res. 102, 301-313 (2010).

[21] E. Snoeks, P. G. Kik, and A. Polman, "Concentration Quenching in Erbium Implanted Alkali Silicate Glass," Opt. Mater. 5, 159 (1996).

[22] D. M. Gill, L. McCaughan, and J. C. Wright, "Spectroscopic Site Determinations in Erbium-Doped Lithium Niobate," Phys. Rev. B 53, 2334 (1996).

[23] M. C. Paul, S. W. Harun, N. A. D. Huri, A. Hamzah, S. Das, M. Pal, S. K. Bhadra, H. Ahmad, S. Yoo, M. P. Kalita, A. J. Boyland, and J. K. Sahu, "Wideband EDFA Based on Erbium Doped Crystalline Zirconia Yttria Alumino Silicate Fiber," J. Lightwave Technol. 28, 2919-2924 (2011).

[24] M. C. Paul, S. W. Harun, N. A. D. Huri, A. Hamzah, S. Das, M. Pal, S. K. Bhadra, H. Ahmad, S. Yoo, M. P. Kalita, A. J. Boyland, and J. K. Sahu, "Performance comparison of $\mathrm{Zr}$-based and Bi-based erbium-doped fiber amplifiers," Opt. Lett. 35, 2882-2884 (2010).

[25] J. R. Armitage, "Spectral Dependence of the Small-Signal Gain around $1.5 \mu \mathrm{m}$ in Erbium Doped Silica Fiber Amplifiers," IEEE J. Quantum Electron. 26, 423-425 (1990).

[26] B. Pedersen, A. Bjarklev, J. H. Povlsen, K. Dybdal, and C. C. Larsen, "The design of erbium-doped fiber amplifiers," J. Lightwave Technol. 9, 1105-1112 (1991).

[27] J. Yang, S. Dai, Y. Zhou, L. Wen, L. Hu, and Z. Jiang, "Spectroscopic Properties and Thermal Stability of Erbium-Doped Bismuth-Based Glass for Optical Amplifier," J. Appl. Phys. 93, 977-983 (2003).

[28] P. Peterka, B. Faure, W. Blanc, M. Karásek, and B. Dussardier, "Theoretical Modelling of S-band Thulium-Doped Silica Fibre Amplifiers," Opt. Quant. Electron 36, 201-212 (2004).

[29] K. Kikuchi, and C. Lorattanasane, "Design of Highly Efficient FourWave Mixing Devices using Optical Fibers," IEEE Photonic. Tech. L. 6, 992-994 (1994).

[30] 0. Aso, A. Shin-Ichi, T. Yagi, M. Tadakuma, Y. Suzuki, and S. Namiki, "Broadband Four-Wave Mixing Generation in Short Optical Fibres," Electron. Lett. 36, 709-711 (2000).

[31] G. D. Wilk, R. M. Wallace, and J. M. Anthony, "Hafnium and Zirconium Silicates for Advanced Gate Dielectrics," J. Appl. Phys. 87, 484-492 (2000).

[32] G. Rayner, R. Therrien, and G. Lucovsky, "The structure of plasmadeposited and annealed pseudo-binary $\mathrm{ZrO}_{2}-\mathrm{SiO}_{2}$ alloys," Proc. Mater. Res. Soc. Symp. 611, C1.3.1-C1.3.9 (2000).

[33] P. F. James, "Liquid-Phase Separation in Glass-Forming Systems," J. Mater. Sci. 10, 1802-1825 (1975). 
[34] G. P. Agrawal, Nonlinear Fiber Optics (Academic Press, London, 1995).

[35] K. 0. Hill, D. C. Johnson, B. S. Kawasaki, and R. I. MacDonald, “CW Three-Wave Mixing in Single-Mode Fibers," J. Appl. Phys. 49, 50980-51006 (1978).
[36] N. Shibata, R. P. Braun, and R. G. Warrts, "Phase-Mismatch Dependence of Efficiency of Wave Generation through Four-Wave Mixing in a Singlemode Fiber," Quantum Electron. 23, 1205-1211 (1987). 